\title{
Effect of Licorice on Wound Healing In Rabbits
}

\author{
Alsayed, A. Zaki*; Mohammed, H. El-Bakry** and Alaa, A. Fahmy ${ }^{* * *}$ \\ Departments of Pharmacology, Faculties of Medicine Cairo ${ }^{*}$ and Assiut ${ }^{* *}$ Branches, \\ Al-Azhar University \& Department of Anatomy, Faculty of Medicine, \\ Ain Shams University ${ }^{* * *}$, Cairo, Egypt
}

\begin{abstract}
Licorice (Glycyrrhiza glabra) is one of the most widely used medicinal plants and is included in numerous traditional and modern medical preparations. In the present study the healing effect of licorice extract was investigated on open skin wounds in rabbits. Adult Newzeland rabbits of both sexes weighing $1.5-2.5 \mathrm{~kg}$ were used. Hairs of lower back and left flank of animal were shaved. Full-thickness wound $(15 \times 15 \mathrm{~mm})$ was made on the shaved area. Hydroalcoholic extract of licorice was prepared by maceration method. Creams of 5\%,10\% and $15 \%(\mathrm{w} / \mathrm{w})$ extract in eucerin base were prepared and applied 2 times daily. Dexpanthenol ointment was used as standard control. Healing was determined by reduction in wound area. The results of this study proved that licorice cream of $10 \%$ was a potent healing agent even better than dexpanthenol cream.
\end{abstract}

\section{Introduction}

Healing of wounds or restoration of tissues integrity is a natural mechanism and normal reaction to injury. Inflammation, proliferation and remodeling, all are the main steps of wound healing. Wound healing in animals and humans is relatively similar (Champion et al., 1998). Many drugs of chemical or natural origin as dexpanthenol, Ginko biloba, phenytoin, zinc oxide, and others have been used topically to improve the rate of wound healing (Lawrence et al.,1995; Hemmati \& Mohammadian, 2000; Bairy \& Rao,2000)).

Licorice (Glycyrrhiza glabra) is a plant that grows wild in Western and Eastern world and has long history of therapeutic uses by cultures throughout the world, including the Greeks, Egyptians, Chinese and Indians. It was tradionally used in treatment of peptic ulcer, asthma, pharyngitis, malaria, abdominal pain, insomnia, infections, and many other diseases (Evans, 1989; Blumenthal et al., 2000; Wang \& Nixon, 2001; Chan et al., 2003). Licorice was also valued in ancient Egypt that King Tutankhamen was buried with a supply (Fleming, 2000; Hart, 2001).

Modern researches on licorice also reported its efficacy in treatment of various diseases. Human studies proved its curative effect in infectious hepatitis (Chang,1986; Tare et al., 2005), chronic hepatitis C, and subacute hepatic failure (Acharya \& Dasarathy, 1993; Fujioka et al., 2003), haemophilia and HIV-1 infection (Mori,1990; Sasaki et al., 2003), gastric and duodenal ulcers (Baker, 1994), and in herpes, eczema, and psoriasis. The antibacterial effect against Staph. aureus, Strept mitans, Mycobacterium smegmatis and Candida albicans (Langmead \& Rampton, 2001) was also documented. Accordingly, licorice is now used in a great variety of pharmaceutical preparations.

However, up till now, the topical effect of licorice on improvement of wound healing has not been investigated. So, the aim of the present work was to evaluate the healing effect of topically applied licorice on skin wounds using rabbits as the experimental animals.

\section{Materials and Methods}

The dried roots of licorice (purchased from Ramzy Bayrakdars and Sons, Syria) was powdered by a grinder. $100 \mathrm{~g}$ of the powder were placed in a beaker and $1000 \mathrm{ml}$ 


\section{Effect of Licorice on Wound Healing In Rabbits}

of ethanol $70 \%$ was added and mixed. The mixture was left at room temperature for 3 days. The extract was filtered using Whatman (No 10) filter paper and concentrated by vacuum evaporation. Creams of $5 \%, 10 \%$ and $15 \%$ licorice extract in eucerin (wool alcohol) were prepared. Dexpanthenol was purchased from Nile Company for Drugs, Cairo, Egypt.

Adult Newzeland rabbits of both sexes weighing $1.5-2.5 \mathrm{~kg}$ were used. They were housed individually at aluminium cages in room temperature around $25{ }^{\circ} \mathrm{C}$. They had access to standard, commercial pellet diet supplemented with fresh vegetables and water ad libitum. The holding room was illuminated with 12 hours light/dark cycles.

A full thickness wound was made in the skin of the test animals according to the model of Cross et al., 1995) as modified by Hemmati, and Mohammadian, 2000). The hair of lower back and left flank of the animals was fully shaved and locally anaesthetized using subcutaneous injection of lidocaine $(2 \%)$. The animals were held in the standard crouching position, and the mobile skin of the flank was gently stretched and held by the fingers. A metal template measuring $15 \times 15 \mathrm{~mm}$ was placed on the stretched skin and an outline of the template was traced on the skin using a fine-tipped pen. The wound was made by excising the skin, within the border of the template to the level of loose subcutaneous tissue, using a forceps and a size 15 scalpel blade. All ethical issues were considered in surgery procedure and during the treatments.

Animals were divided into six groups, each included six rabbits. Wounds of one group were left without any treatment. Eucerin base was applied to the wounds of the second group. The third group was treated topically with dexpanthenol cream as a standard healing agent. The remaining three groups were treated topically with eucerin containing licorice extract (5\%, $10 \%$ and $15 \%$, respectively). Wound dressings were done twice daily, and bedding in the animal cages was changed twice daily. Cages were kept clean to avoid infection of wounds.

The rate of wound healing was quantified daily. The animal was held in the standard crouching position and outline of the wound was traced on a transparent plastic sheet using a fine- tipped pen. Measurements errors were minimized by repeating each measurement three times at the same sitting and the average of this measurement was used in all calculations. The area of the wounds on the first day was considered as $100 \%$ and the wound areas on subsequent days were compared with the wound on the first day. Healing percentage was the difference between the initial wound and the healing wound.

Statistical analysis of data was done using Student's $t$ test. A value of $p<0.05$ was considered significant. Data are presented as means \pm standard errors $(\mathrm{M} \pm \mathrm{SED})$ of means.

\section{Results}

The rate of wound healing was nearly the same in untreated animals and animals subjected to topical application of eucerin base. In both groups healing was completed within 21 days (Fig. 1). Dexpanthenol treatment cut short the time of wound healing to 19 days (Fig 2). All three concentrations of licorice extract showed better rate of wound healing than dexpanthenol. With licorice extract creams of $5 \%, 10 \%$, and $15 \%$, wound healing was completed within 16, 14, and 15 days, respectively (Fig 3). Licorice cream of 10 $\%$ concentration exhibited the best healing rate. Significant differences between $10 \%$ licorice extract-treated group and dexpanthenol-treated groups was observed (Fig. 4). The wound healing effect of $10 \%$ licorice extract cream was more pronounced compared with dexpanthenol ointment. The healing effect of the $10 \%$ concentration of licorice compared with the eucerin-treated group was also evident $(\mathrm{P}<$ $0.05)$ as early as the second day of treatment and continued to the end of the treatment course (Fig. 5). 
Fig. 1 Untreated animals \& animals subjected to topical eucerin. Values significantly different from no treatment ar indicated as ${ }^{\star}(P<0.05)$

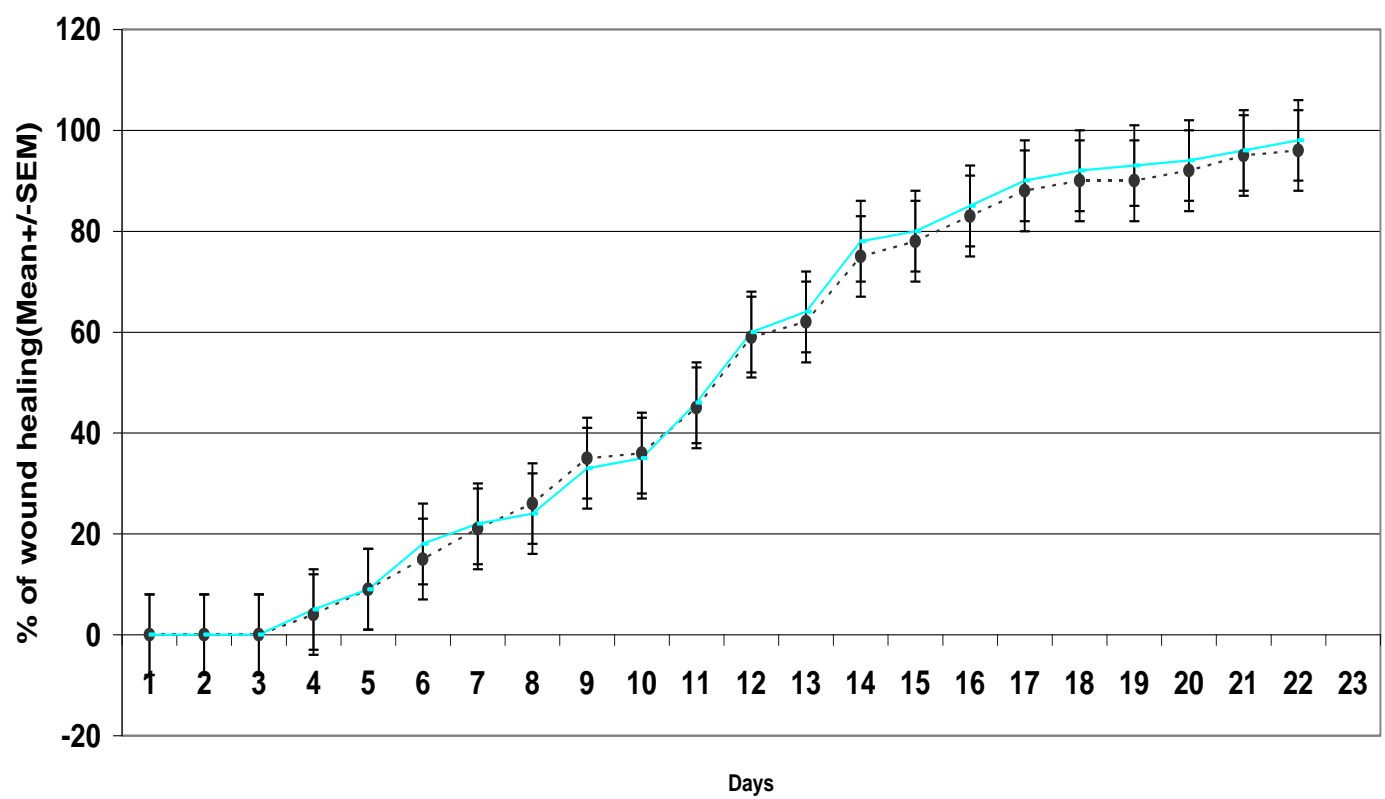

\section{-.. No treatment — Eucerin}

Fig. 2 Comparison of the wounds healing in eucerin \& dexpanthenol treated groups. Values significantly different from eucerin are indicated as ${ }^{*}(P<0.05)$ or ${ }^{\star *}(P<0.01)$

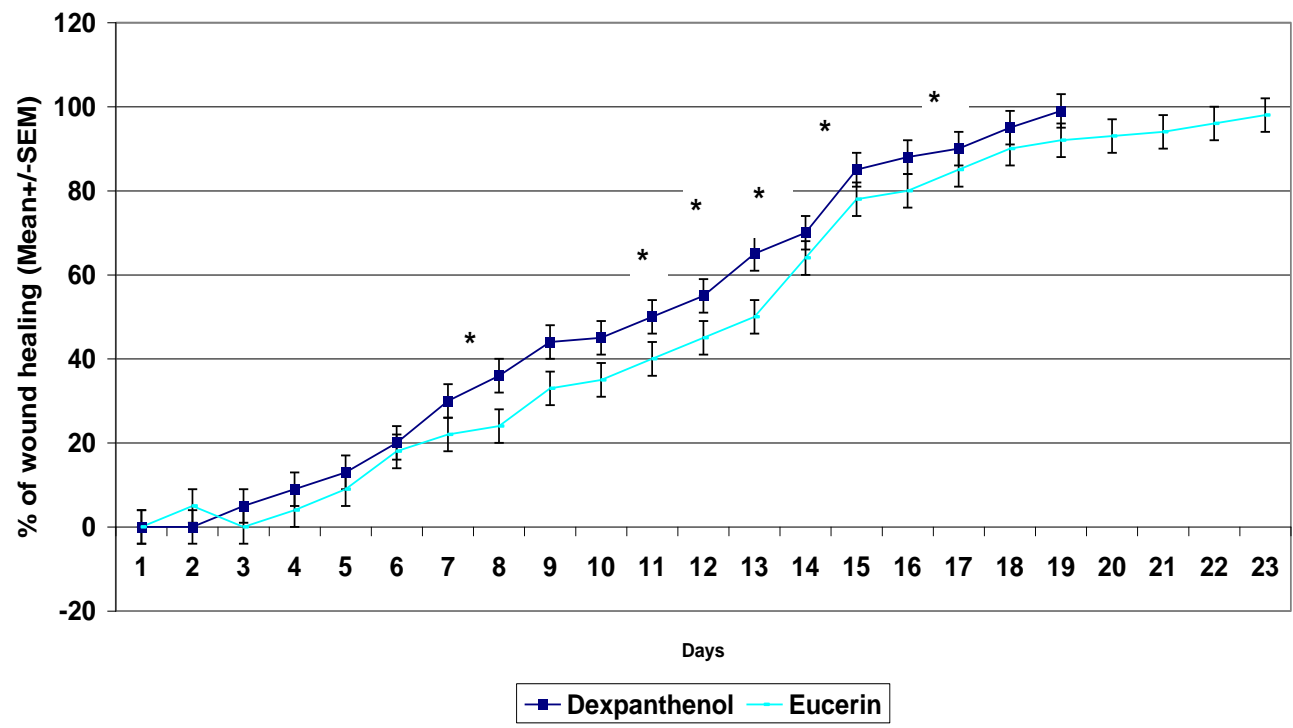


Fig. 3 Comparison of the wound healing in dexpanthenol \& licorice extracts treated groups. Values significantly different indicated as ${ }^{\star}(P<0.05)$ or ${ }^{\star *}(P<0.01)$

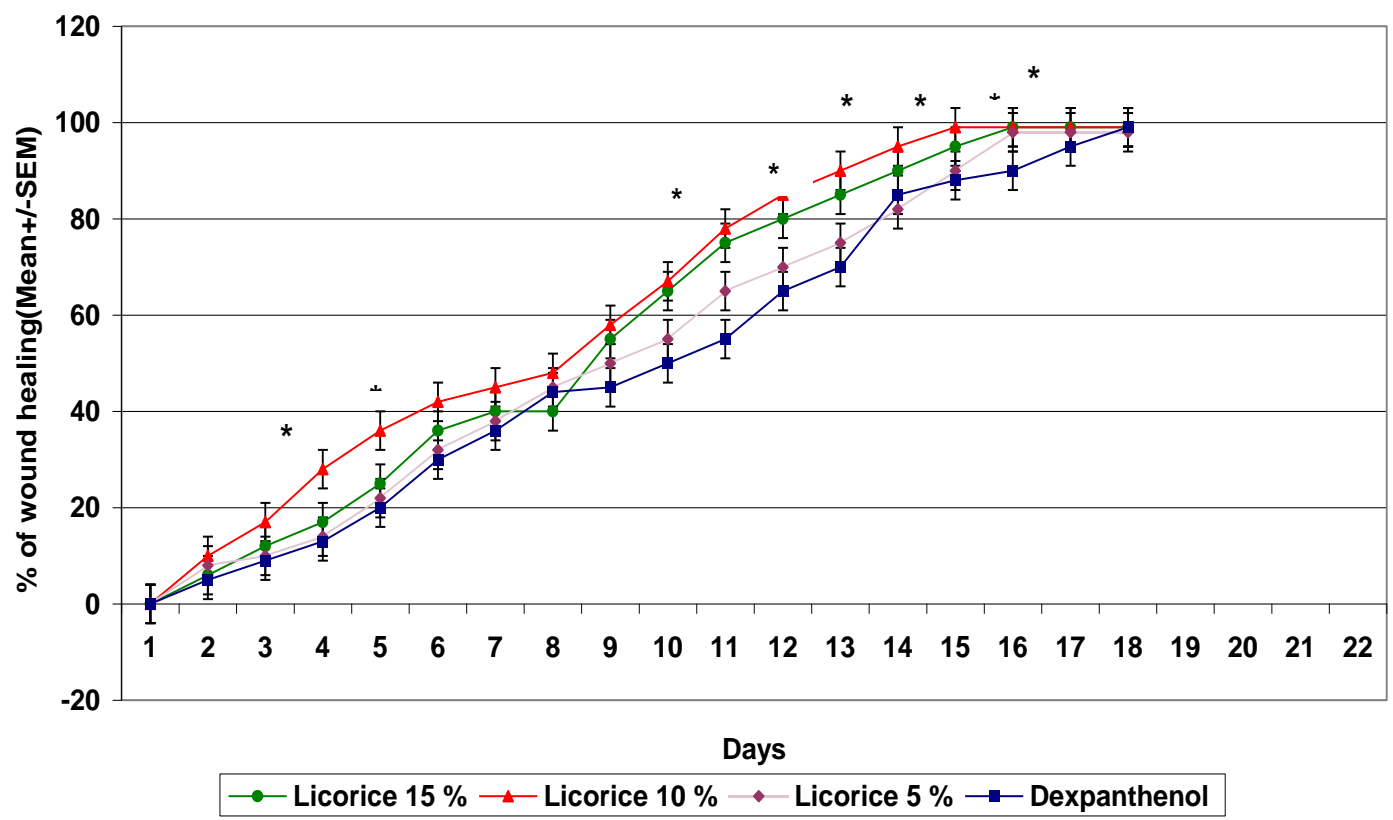

Fig. 4 Comparison of wound healing in dexpanthenol \& licorice extracts cream $10 \%$ treated groups.Values significantly different from dexpanthenol are indicated as ${ }^{*}(P<0.05) 0 R^{\star *}(P<0.01)$

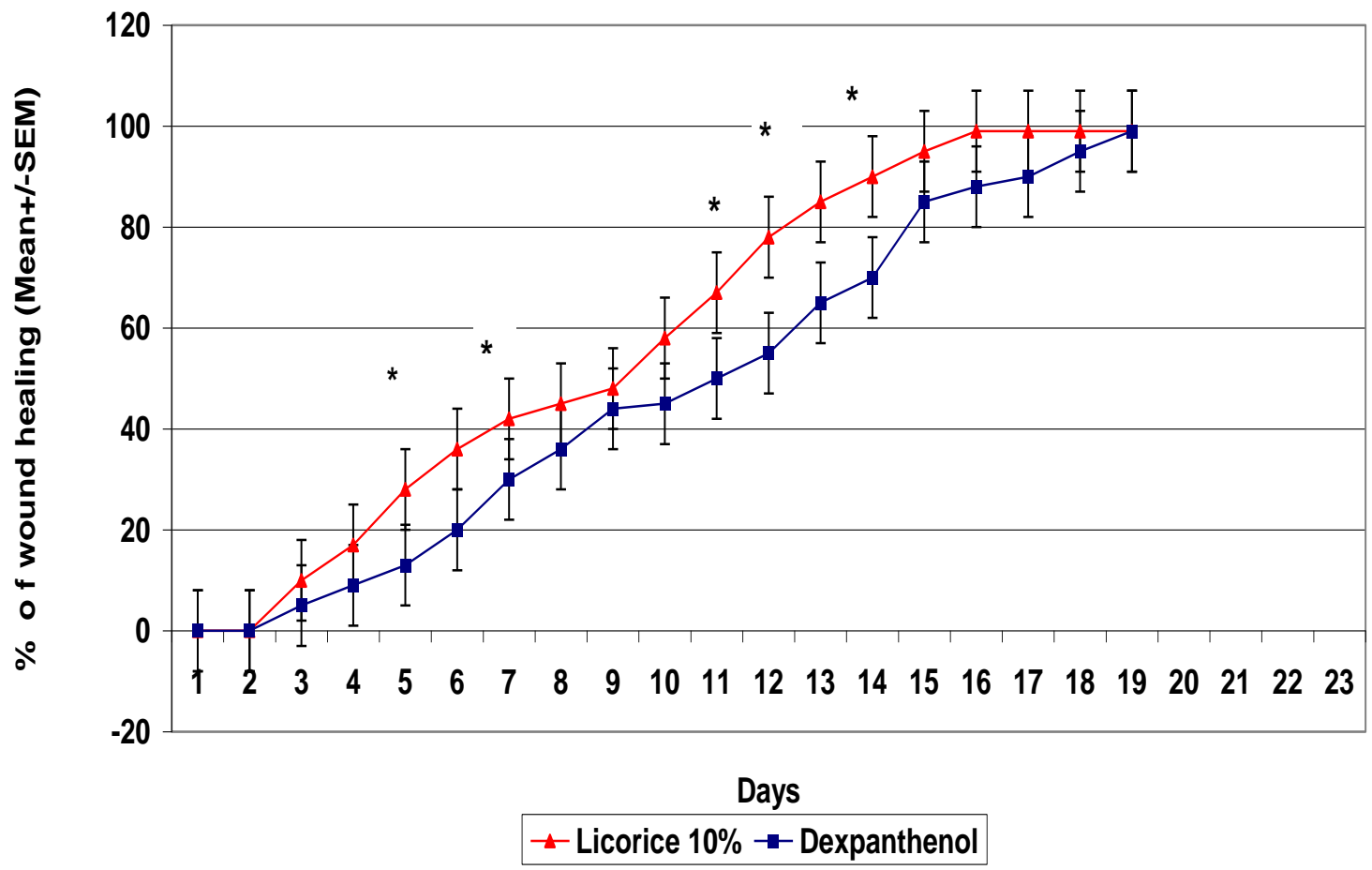


Fig. 5 : Comparison of the wound healing in eucerin \& licorice extract cream $10 \%$ treated groups. Values significantly different from eucerin are indicated as * $(P<0.05)$ or ${ }^{* *}(P<0.01)$

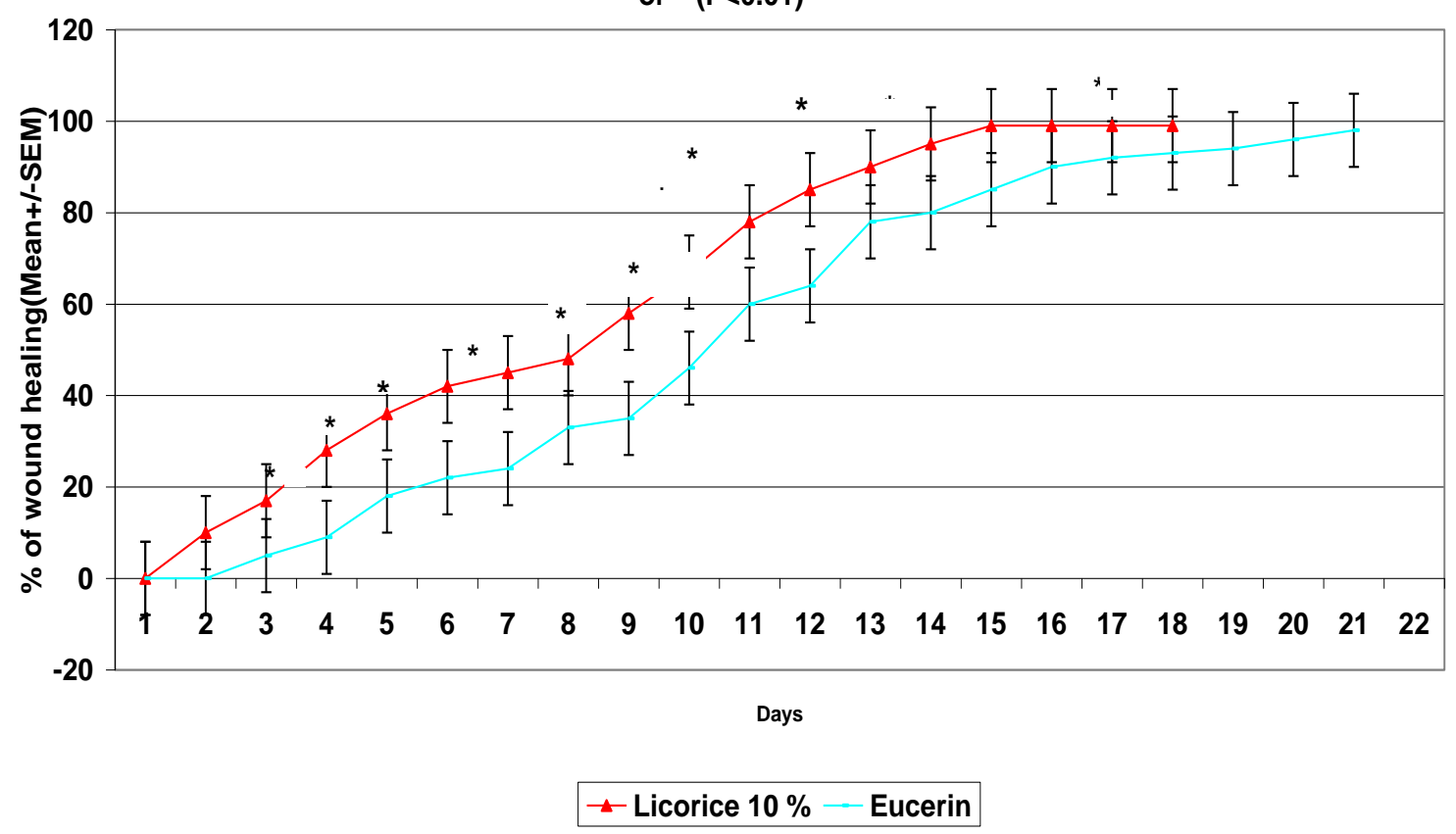

\section{Discussion}

Healing of wound involves various phases such as inflammation, coagulation, collagenation, wound contraction and epithelialisation. Although the coagulation and collagenation phases are interlinked, yet, wound contraction and epithelialisation are completely independent from each other but run concurrently (Bairy \& Rao, 2000; Wynne et al., 2004).

In the present work, an excision skin wound model for contraction and epitheliali -sation was employed in rabbits and the healing effect of licorice extract on the skin wound model was investigated.

The obtained results demonstrated that licorice extract reduced the time required for wound healing indicated by the faster contraction of the wound treated with licorice extract in comparison with untreated ones or those subjected to topical application of the vehicle eucerin. The percentage of healing with different concentrations of licorice extract were significantly $(p<0.05)$ higher than eucerin group from the second day of treatment until the complete closure of wound. Again licorice extract was more potent than dexpanthenol which is a standard healing agent. The $10 \%$ licorice cream was the most efficient as it cut down the duration of wound healing to 14 days only.

Although numerous studies have been done regarding the pharmacological properties of licorice (Baker, 1994; Blumenthal et al., 2000; Shibata, 2000; Rotblatt \& Ziment, 2004; Mike \& Stew, 2005), yet, the mechanism by which this plant promotes healing has not been well documented. Few studies have been done to elucidate the mechanisms of the action of licorice on peptic and duodenal ulcers. It may increase the synthesis prostaglandin $\mathrm{E}$ which is protective for the gastrointestinal mucosa (Borrelli \& Izzo, 2000; Langmead \& Rampton, 2001; Cinati et al., 2003; Lin, 2003; Fukai et al., 2004). Furthermore, it has been shown that licorice may promote the production of mRNA and new proteins which are involved in the process of wound healing (Safayhi \& Sailer, 1997). It is also proved that licorice has a cortisol-like effect on healing of wounds including inhibition of inflammation by inhibiting phospholipase $A_{2}$ (first step in the synthesis of 


\section{Effect of Licorice on Wound Healing In Rabbits}

inflammatory prostaglandins and leukotrienes) (Haraguchi et al., 2000; Armanini et al., 2002; Fujoka et al., 2003; Hart, 2004).

Chemically , glycyrrhizin (6-10\%), is the most important active ingredient in licorice besides other important constituents which include flavonoids, isofalvonoids, chalcones, coumarins, tritepenoids, sterols, starch $(2-20 \%)$, sucrose, glucose $(3-4 \%)$, liginins, amino acids, amines, gums, and volatile oils (Hart, 2004; Mike \& Stew, 2005). Glycyrrhizin proved to increase interleukin 2 which is essential for wound healing (Acharya \& Dasarathy, 1993; Yokota et al., 1998; Wynne et al., 2004). The isoflavonoids show in vitro activity against Staph. aureus, Strept. mitans, Mycobacterium smegmatis and Candida albicans (Shibata, 2000; Saeedi et al., 2003; Mike \& Stew, 2005); organisms that cause infections and delay wound healing.

However, more studies are required to elucidate the exact mechanism of licorice extract in wound healing.

\section{Conclusion}

The present work demonstrated the healing effect of licorice on wounds. Although the exact mechanism by which licorice improves wound healing is not yet clear, however, it is advisable to be used with other medications to cut short the time of wound healing and further investigations has to be done to clarify the exact mechanism by which licorice promotes wound healing.

\section{References}

1- Acharya, S.K \& Dasarathy, A. (1993): A preliminary open trial on interferon stimulator (SNMC) derived from Glycyrrhiza glabrra in the treatment of subacute hepatic failure. Indian, J. Med. Res, 98: 69-74.

2- Armanini, D. (2002): History of the endocrine effects of licorice. Exp. Clin. Endocrinol Diabetes, 110, 6:257-61.

3- Bairy, K. L., Rao, C.M. (2001): Wound healing profile of Ginko biloba. J. Natural Remedies, 1: 25-27.
4- Baker, M.E. (1994): Licorice and enzymes other than 11 B-hydroxy steroid dehydrogenase, an evalutionary prospective. Steroids, 59:136-141.

5- Blumenthal, M., Golgerg, A., Brinckmann, J. (2000): Herbal Medicine. Integrative Medicine, Newtown M.A., 233239.

6- Borrelli, F., \& Izzo, A.A. (2000): The plant kingdom as a source of anti-ulcer remedies. [Review]. Phytother Res. 14(8):581-591.

7- Champion, R.H., Burton, J. L., Burns, O. A., Breathnach, S. M. (1998): Textbook of dermatology. Blackwell Science, Oxford, 337-339

8- Chan, H. T. et al., (2003): Inhibition of glycyrrhizic acid on aflatoxin B1-induced cytotoxicity in hepatoma cells. Toxicology. 188 (2-3):211-7.

9- Chang, H. M., But, P.P.H. (Eds) (1986): Pharmacology and applications of Chinese materia medica. Vol. I Philadelphia World Scientific, 304-331.

10- Cinatl, J. (2003): Glycyrrhizin, an active component of liquorice roots, and replication of SARS-associated coronavirus. Lancet. 361, 9374: 2045-6.

11- Cross, S.E., Naylor, I.L., Coleman, R. A., Teo, T.C. (1995): An experimental model to investigate the dynamics of wound contraction. Br. J Plastic Surgery, 48:189-197.

12- Evans, W.C., Trease, \& Evans (1989): Pharmacognosy, W. B, Saunders Company. London, 55 - 166.

13- Fleming, T., (2000): PDR for herbal medicines. Medical Economics Company. Montvale, New jersey, 833-835.

14- Fukai, T. (2004): Anti-Helicobacter pylori flavonoids from licorice extract. Life Sci. 71, 12:1449-63.

15- Fujioka, T., Kondou, T., Fukuhara, A., (2003): Efficacy of a glycyrrhizin suppository for the treatment of chronic hepatitis C: a pilot study. Hepatol Res, 26(1):10-14.

16- Hart, M. D., (2004): Department of Internal Medicine, Newton-Wellesley Hospital, Harvard University , Boston, MA; Gary, Kracoff, R.Ph. (2001) (Pediatric Dosing section February), Johnson Drugs, Natick, M.A; Steven Ottariono, R. Ph., N.H. R. Copyright (C (2004) A.D.A.M., Inc

17- Haraguchi, H. (2000): Protection of mitochondrial functions against oxidative stresses by isoflavans from glycyrrhiza glabra. J. Pharm Pharmacol. 52, 2:219-23. 
18- Hemmati, A.A., Mohammadian, F. (2000): An investigation into the effect of mucilage of quince seeds on wound healing in rabbit. J. Herbs Spices Medicinal Plants, 7: 41-46.

19- Langmead, L., Rampton, D.S. (2001): Review article: herbal treatment in gastrointestinal and liver disease--benefits and dangers. [Review]. Aliment Pharmacol Ther. 15(9):1239-1252.

20- Lawrence, C.M, Mathews, I.N., Cox, N.H. (1995): The effect of ketanserin on healing of fresh surgical wounds. Br J Dermatol, 132: 580-586.

21- Lin, J.C. (2003): Mechanism of action of glycyrrhizic acid in inhibition of EpsteinBarr virus replication in vitro. Antiviral Res. 59, 1:41-7.

22- Mike Darnofall \&Stew Eckard. (2005): Licorice, Description, Chemical composition, and pharmacological effects. Text Book of natural medicine. Pima Publishing. Procklin CA., P 120.

23- Mori K. (1990): Effect of glycyrrhizin in hemophilia patients with $\mathrm{H} 1 \mathrm{~V}-1$ infection. Tokyo J. Exp. Med., 162: 183-193

24- Rotblatt, M., Ziment, I. (2004): EvidenceBased Herbal Medicine. Philadelphia, P.A: Hanley \& Belfus, Inc., 252-258.

25- Saeedi, M., Morteza-Semnani, K., Ghoreishi, M.R. (2003): The treatment of atopic dermatitis with licorice gel. J. Dermatolog Treat. Sep. 14(3):153-7.
26- Safayhi, H., Sailer, E.R. (1997):Antiinflammatory actions of pentacyclic triterpenes. Planta Medica. 63: 487-493.

27- Sasaki, H. (2002): Effect of glycyrrhizin, an active component of licorice roots, on HIV replication in cultures of peripheral blood mononuclear cells from HIVseropositive patients. Pathobiology. 70, 4:229-36.

28- Shibata, S. A. (2000): Drug over the millennia: pharmacognosy, chemistry, and pharmacology of licorice. [review] Yakugaku Zasshi. 120(10):849-862.

29- Tare, M. H. A., Coleman, and H. C. Parkington, (2005): Glycyrrhetinic derivatives inhibit hyperpolarization in endothelial cells of guinea pig and rat arteries. A. J. Physiol., Heart Circ Physiol., January 1, 288: H48-H54.

30- Yokota, T., Nishio, H., Kubata, Y., Misogushi, M. (1998): The inhibitory effect of glabridin from licorice extracts on melanogenesis and inflammation. Pigment Cell Res, 355-361.

31- Wang, Z.Y., Nixon, D.W. (2001): Licorice and cancer. Nutr. Cancer, 29 (1):1-11.

32- Wynne, R., Botti, M., Stedman, H., Holsworth, L., Harinos, M., Flavell, O., Manterfield, C (2004): "Effect of three wound dressings on infection, healing comfort and cost in patients with sternotomy wounds: a randomized trial" Chest 125 43-49. 


\section{تأثير عرق السوس على التئام الجروح في الأرانب}

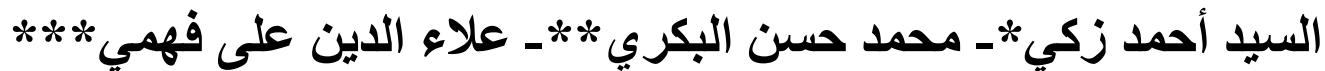

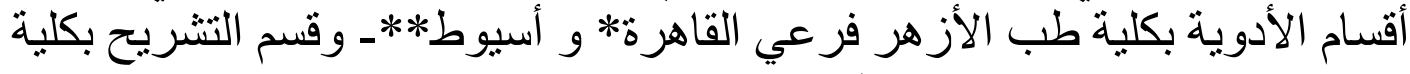

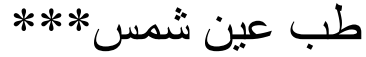

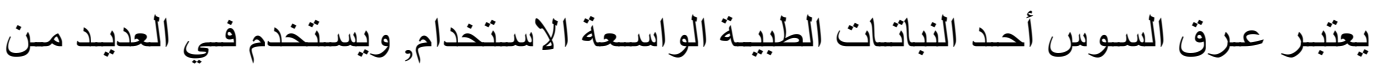

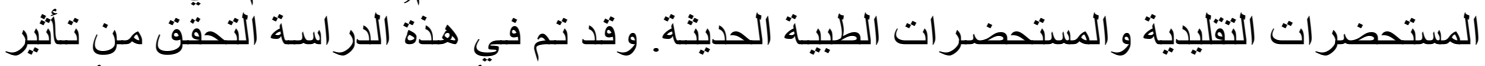

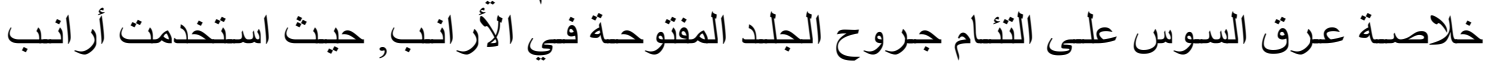

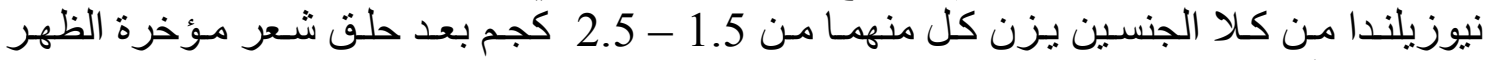

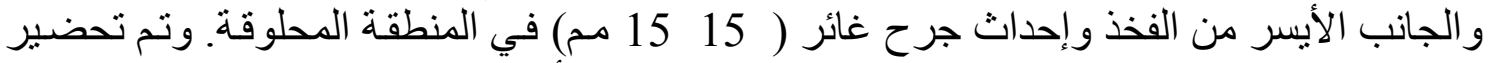

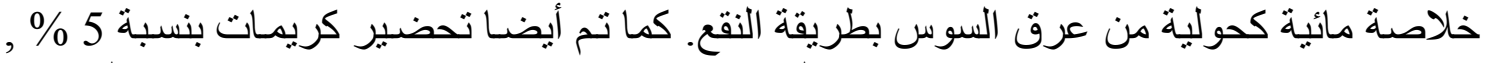

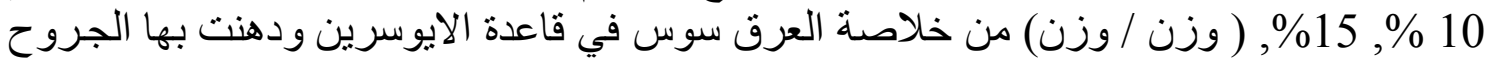

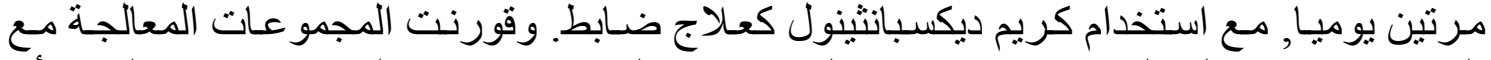

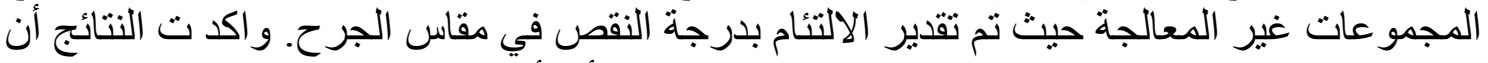
كريم عرق السوس (10 \%) هو عامل التئام فعال, بل وجد أنة أفضل من كريم ديكسبانثينول. 